Western Washington University

Western CEDAR

\title{
The Evolution of ADHD: A Disorder of Communication?
}

Joan C. Stevenson

Western Washington University, joan.stevenson@wwu.edu

Don C. Williams

Western Washington University

Jessica Baird

Western Washington University

Follow this and additional works at: https://cedar.wwu.edu/anthropology_facpubs

Part of the Anthropology Commons

\section{Recommended Citation}

Stevenson, Joan C.; Williams, Don C.; and Baird, Jessica, "The Evolution of ADHD: A Disorder of Communication?" (2000). Anthropology Faculty and Staff Publications. 10.

https://cedar.wwu.edu/anthropology_facpubs/10 


\section{CHICAGO JOURNALS}

The Evolution of ADHD: A Disorder of Communication?

Author(s): Jessica Baird, Joan C. Stevenson and Don C. Williams

Source: The Quarterly Review of Biology, Vol. 75, No. 1 (Mar., 2000), pp. 17-35

Published by: The University of Chicago Press

Stable URL: http://www.jstor.org/stable/2664498

Accessed: 23/10/2014 14:49

Your use of the JSTOR archive indicates your acceptance of the Terms \& Conditions of Use, available at

http://www.jstor.org/page/info/about/policies/terms.jsp

JSTOR is a not-for-profit service that helps scholars, researchers, and students discover, use, and build upon a wide range of content in a trusted digital archive. We use information technology and tools to increase productivity and facilitate new forms of scholarship. For more information about JSTOR, please contact support@ jstor.org. 


\title{
THE EVOLUTION OF ADHD: A DISORDER OF COMMUNICATION?
}

\author{
JESSICA BAIRD \\ Department of Biology, Western Washington University \\ Bellingham, Washington 98225 USA \\ Joan C. Stevenson \\ Department of Anthropology, Western Washington University \\ Bellingham, Washington 98225 USA \\ E-MAIL: JCSTVNSN@CC.WWU.EDU \\ Don C. Williams \\ Department of Biology, Western Washington University \\ Bellingham, Washington 98225 USA \\ E-MAIL: WILLIAMS@BIOL.WWU.EDU
}

ABSTRACT

Attention deficit hyperactivity disorder (ADHD) is the most commonly diagnosed psychiatric condition. Many believe that the central disability is impaired inhibition, which leads to reduced abilities in social skills, self-control, organization and time management. The behaviors identified by clinicians as problematic-inattention, hyperactivity and impulsivity-have been incorporated into several evolutionary models as selectively adaptive cognitive skills for surviving the challenges of a variable Pleistocene environment. We propose that the "disabilities" exhibited by individuals with ADHD are maladaptive, and we concur with Barkley that there is a central impairment in the behavioral inhibition system. The underlying neural anatomy and physiology support the possibility that neurotransmitter pathology may have an impact on other interlinked systems (including language), and may also account for the frequent comorbidity of aggression, anxiety, depression, and learning disabilities (many of which are language-related). Language skills compete with other cognitive activities for the attentional system, and thus the evolution of language could not in fact be independent of the evolution of attention. If language represents the ultimate expression of the attentional system, and some individuals with $A D H D$ are seriously impaired in the coordination of interlinked neural systems (including language), then ADHD fits Jerome Wakefield's definition of "harmful dysfunction," and communication impairments should be investigated more thoroughly by clinicians.

The Quarterly Review of Biology, March 2000, Vol. 75, No. 1

Copyright $(2000$ by The University of Chicago. All rights reserved.

0033-5770/2000/7501-0002\$02.00 


\section{INTRODUCTION}

A TTENTION deficit hyperactivity disorder (ADHD) is the most frequently identified psychiatric condition in children. It includes behaviors that seem to impair performance in social skills, self-control, and time management; such impairments can interfere with an individual's ability to succeed socially in terms of relationships or a career (Barkley 1990, 1997a,b; Castellanos 1997; Goldman et al. 1998). ADHD is usually passed from parent to offspring, with heritability averaging 0.80 (Barkley 1997b), and it has been identified in 3 to $9 \%$ of the population (Richters et al. 1995). Hartmann (1993), Jensen et al. (1997b), and Shelley-Tremblay and Rosen (1996) assert that ADHD's especially high heritability for a behavioral disorder and its relatively high occurrence imply that it was selectively advantageous, particularly in prehistoric environments. Hartmann argues that individuals with ADHD share behavioral traits with "hunters," while individuals without the disorder share traits with "farmers." Shelley-Tremblay and Rosen do not feel that the demands of hunting were sufficient to explain the behavioral configuration typical of ADHD; they note that, given certain ancestral scenarios, an increase in aggression and the tendency to hypervocalize and be more physically and verbally "connected" to mother, could also be favored. Jensen et al. propose that typical ADHD symptoms are part of a "response-ready" behavioral configuration that would have been superior to a more thoughtful, slower acting, "problemsolving" mind-set in the ever-changing environments typical of the Pleistocene.

These models are provocative, but our premise is that the underlying assumptions are flawed, and that ADHD behaviors are not particularly advantageous in any setting. Because many genes are likely to be involved (Levy et al. 1997), the disadvantage is analogous to being short rather than tall when trying to obtain jobs where height is an advantage. Individuals with ADHD are not missing any cognitive features typical of human beings. They do seem, however, to be less effective in the implementation, control and monitoring of those cognitive processes.

Barkley (1997b) reviews a broad range of studies and contends that there is one primary disability-poor behavioral inhibition-that is the central impairment in individuals with ADHD; this impairment results in deficiencies in self-control. Human beings exhibit relatively sophisticated levels of self-regulation, which is evident in the way individuals are able to temper or postpone actions or responses until they have reflected upon the past and anticipated the future. This self-regulation is also informed by the actions and motives of others. Our conclusion is that the ultimate source of the most recently evolved refinements in inhibition skills lies in the selective pressures that have added successive layers to human communication (Corballis 1999). Once the human brain made the connection between referent and symbol, a selectively favored feedback system was set in motion (Deacon 1997). The resulting chain reaction favored a unique information exchange system that permitted increasing sophistication in manipulating the physical and social environments, one that also demanded increasing abilities in self-regulation, attention and memory.

The idea that unique human cognitive features (and even disorders, e.g., Crow 1997) are a side effect of the development of the human communication system is not a new one (e.g., Vygotsky 1934; Bronowski 1977; Berk 1992). We will argue that self-inhibition or self-control is so closely intertwined with the most recently evolved aspects of language that many of the disorders that associate (are comorbid) with attention deficit disorder reflect an underlying set of interconnected neural subsystems. The objective here is to review the ADHD "selective advantage models," to develop the "side effect of human language evolution model of ADHD" from neurochemistry and neuroanatomy to behavior, and to identify implications for the treatment of people with this "disorder." In order to do this, the nature of ADHD, as it has been characterized in recent editions of APA's The Diagnostic and Statistical Manual of Mental Disorders (DSM-IV) (American Psychiatric Association 1994), will also be briefly reviewed. If individuals with ADHD represent one tail of a normal distribution, then the "pathology" threshold identified by clinicians will vary, depending to some extent on how challenged these individuals are in a particular situation. 


\section{IDENTIFICATION OF INDIVIDUALS WITH ADHD}

Children tend to be impulsive, physically active, easily bored, and prone to shift activities frequently. When these behaviors are excessive and consistently exhibited in inappropriate settings, however, these individuals are less likely to succeed in a variety of social contexts (Barkley 1997a,b). Those with ADHD have a reduced ability to follow instructions, are less likely to persevere at boring tasks, and are averse to delays (Barkley et al. 1990; SonugaBarke et al. 1992). Their ability to estimate time accurately is diminished, and scheduling problems are so common that those afflicted can be relatively ineffective in achieving future goals (Barkley 1994b). Mental arithmetic is extremely challenging, and internal verbalization is delayed, producing speech that is often excessive and irrelevant.

The diagnostic tool for recognizing the disorder, the $D S M-I V$, requires that behaviors such as inattention (e.g., disorganization, forgetfulness, distractibility, poor task persistence), poor impulse control and hyperactivity appear "often" before they can be considered symptoms of ADHD. Barkley (1997b) notes that only 7 to $23 \%$ of normal boys and only 4 to $19 \%$ of normal girls "often" exhibit any of the symptoms defined by the DSM-IV. No single symptom is sufficient, and at least six or more symptoms must occur "often" on one of two dimensions (inattention or hyperactivity/ impulsivity) for an individual to be diagnosed with the disorder. A pattern must also exist, starting in childhood, that shows up in more than one context and that has led to impairment in a significant aspect of an individual's life (APA 1994:83-85). If the above behaviors are exhibited over a period of six months, three subtypes can then be distinguished. Individuals can exhibit six or more behaviors across both dimensions (combined type), or exhibit six behaviors in only one of the two dimensions (either predominantly inattentive or predominantly hyperactive-impulsive). This variation probably reflects both differential expression along a developmental continuum and an underlying heterogeneity due to complex etiology, supported by the comorbidity of other disorders, such as antisocial behaviors, Tourette syndrome, and learning disabilities
(Hallowell and Ratey 1994; Barkley 1997b; Castellanos 1997). Application of the criteria varies, but ADHD appears to be a worldwide phenomenon, since it is found in every location where it has been studied, with occurrence rates ranging from around $2 \%$ in the U.S. (with stricter criteria) to $29 \%$ in a sample from India (Barkley 1998a).

Studies performed on twins do not support the belief that shared environment has much influence on the occurrence of ADHD (0 to $13 \%$ ), but there is some indication for variance due to nonshared and nongenetic factors (9 to 20\%) (reviewed by Barkley 1998b). Environmental toxins may also play a role in the expression of ADHD, but supporting evidence is limited (Barkley 1997b). Exposure to alcohol and tobacco smoke may also be a factor, but individuals with ADHD use drugs more often than do control samples, so it is not clear whether these behaviors are a cause or an outcome of the disorder (e.g., Milberger et al. 1997).

Although attention deficit disorder (ADD) and ADHD are relatively new terms (Barkley et al. 1990), the disorder has been recognized for at least 100 years (Hallowell and Ratey 1994). And even earlier, Shakespeare describes one of the characters in King Henry VIII as having a "malady of attention" (Barkley 1997b:4). Although clinicians took an interest in the disorder after the early 1900 s, most took notice after the encephalitis epidemics of 1917-1918, when the resulting behavioral problems of encephalitis formed a pattern of similar symptoms. This behavioral configuration was initially labeled "brain-injured child syndrome," and later "minimal brain damage," whether or not there was evidence for brain damage (Barkley 1997b:4-9). By the 1960 s, investigators focused on the hyperactivity and reduced impulse control, designating the behavior as "hyperkinetic impulse disorder," thought to be caused by overstimulation resulting from inappropriate filtering of incoming messages. By the second edition of the DSM-II (APA 1968), all childhood disorders were considered reactions (hyperkinetic reaction of childhood), brain damage was rejected in its etiology, and evidence of attention deficit and behavioral distractibility were combined with hyperactivity/restlessness symp- 
toms in order to make a diagnosis (Barkley 1997b). In the 1960s, research interest shifted toward impulse control issues (e.g., Douglas 1972,1983 ), and the disorder was renamed "attention deficit disorder" (APA 1980). The $D S M-I I I-R$ (APA 1987) distinguished ADD with and without hyperactivity, and by the fourth edition of the DSM (APA 1994), the third "combined" designation was added.

Under the current definitions, the disorder first appears between three and seven years of age, lasts into adolescence in about $80 \%$ of the cases, and continues into adulthood as much as $66 \%$ of the time (Barkley 1997a,b). The disorder is more common in males, with the ratio of affected males to females ranging from 9:1 to $6: 1$ in clinic referrals, and about 3:1 in population-based samples (APA 1987; Szatmari 1992).

In 1902, Still was the first to suggest that children with ADHD might have impairments in the brain, and that the disorder may be related to inheritance (Barkley 1994a). His insight was supported by numerous investigators who found shared characteristics in individuals with ADHD and in people with frontal lobe lesions; characteristics such as impaired attention and inhibition, poor regulation of emotion and motivation, and time management problems (e.g., Heilman et al. 1991). Zametkin et al. $(1990,1993)$ found that glucose uptake was reduced in various parts of the brain for ADD patients, and that the decrease was most dramatic in the prefrontal and premotor regions. Barkley (1997b:32-36) reviewed the extensive literature on this subject and noted reduced arousal and a decrease in blood flow to the prefrontal regions and its connections to the limbic system. These reductions occur in the striatum, specifically its anterior region (caudate nucleus). Also, some structures in the brain are consistently smaller in ADD patients, including the right hemisphere plana temporale and the corpus callosum near the genu, splenium and rostral body.

The cerebella in 57 boys with ADHD exhibited relatively smaller volumes of both prefrontal and basal ganglia (frontostriatal structures) when compared with 55 healthy matched controls. The caudate nucleus and the globus pallidus (although not the putamen) were also significantly smaller in the ADHD patients (Castellanos et al. 1996). Casey et al.
(1997) found that the performance of individuals with ADHD improved, depending on the relative size of some of these structures and the individual's age. The right caudate volume decreased with age in the matched controls, and performance improved with age in both groups. This finding supported the idea of a developmental lag in patients with ADHD (e.g., Pontius 1973; Gualtieri and Hicks 1985; Castellanos 1997). Berquin et al. (1998) measured the areas and volumes of the cerebellar vermis (median region of cerebellum between two hemispheres) and found that they were consistently smaller in boys with ADHD. These differences remain even after controlling for brain volume and intelligence quotient (IQ).

In summary, many researchers have tried to provide explanatory frameworks for ADHD, especially after it was discovered that stimulants such as Benzedrine (Bradley 1937) and methylphenidate (Ritalin) help many afflicted with the disorder (reviewed by Barkley 1977; Wilens et al. 1995).

\section{The Centrality of a Self-Inhibition Deficienciy}

The most compelling and theoretically robust explanation for ADHD at present is that of Barkley (1997a,b), who builds on the work of predecessors (Douglas 1972, 1983, 1988; Quay 1988, 1997; Pennington et al. 1993; Schachar et al. 1995; Denckla 1996). All argue that there are underlying deficits in the behavioral inhibition system. Barkley's contention is that there is one primary disability in ADHD-a reduced ability to inhibit responses. This primary factor can play out in several ways. First, an individual may be hindered in inhibiting a "prepotent" response, which Barkley defines as "that response for which immediate reinforcement (positive or negative) is available or with which reinforcement has been previously associated" (1997b:48). Second, an individual may have trouble either ceasing or persisting in an ongoing response. Third, an individual may have difficulty in preventing interruptions from distractions. Barkley (1997b) reviews the extensive empirical evidence that supports inhibitory response deficits in individuals with $\mathrm{ADHD}$ in all three of these areas. The contexts in which these deficiencies are most apparent are: 1) situations where there are time lags be- 
tween events, responses and outcomes, 2) conflicts between immediate and delayed outcomes, and 3) situations where fresh, original responses are required (Barkley 1997b:63).

Barkley (1997b) frames these deficits within Bronowski's (1977) theory of executive functions, and also incorporates elements of Fuster's $(1989,1995)$ neuropsychological functions of the prefrontal cortex and GoldmanRakic's (1995) ideas about working or representational memory. Bronowski comments on the unique aspects of human language and notes that communication requires reflection when alternate options are considered and eventually tried; such reflections require a temporary suspension of action. "Executive functions" are defined as abilities that help maintain plans (problem-solving sets) for accomplishing future objectives (Welsh and Pennington 1988:201-202). Bronowski believes that there are four executive functions: 1) prolongation (the ability to mentally jump around in time and plan for different contingencies); 2) separation of affect (the idea that an individual can separate emotional response from musings on a topic); 3) internalization (internal dialogue); and 4) reconstitution (original and innovative speech constructions). Fuster further notes how important it is for individuals to be able to manipulate arousal states in the execution of behaviors; all of the above perceptions are tied to the developmental process by which speech becomes internalized. Fuster is also convinced that these functions are localized to the prefrontal cortex.

Barkley (1994b) was the first to tie all of the above ideas together into one theory. He points out that reduced control of inhibition interferes with working memory, planning and reflection, and is demonstrated in a slower acquisition of internal speech, so that thoughts and emotions are more likely to be overtly expressed. This disrupts the ability to judge and manage time, or to internally evaluate and execute behaviors designed to accomplish a future goal. He considers individuals with ADHD to be developmentally delayed in the acquisition of these skills, and argues that individuals with ADHD will become somewhat more adept in these areas as they age (but often remain behind their peers). He thus believes that diagnostic criteria should be ad- justed for age, and that older individuals previously diagnosed with ADHD may have outgrown the criteria rather than the disorder. In particular, the symptoms of hyperactivity and impulsivity decline dramatically with age, unlike inattention symptoms that change less (Hart et al. 1995). Again, these trends may be an artifact of inappropriate criteria for different age levels (Barkley 1997b).

Much of the maladaptive behavior is explained as selectively advantageous in ancestral settings. For example, Hartmann (1993:13) argues that individuals with ADHD are "leftover hunters," and reinterprets the behavioral issues described above as part of a set of hunting skills. For example, he suggests that individuals with $\mathrm{ADHD}$ have enhanced abilities for constantly monitoring their environment, especially during a hunt. He believes that these individuals make necessary decisions quickly, and are creative, energetic risk-takers who are demanding of the individuals around them. Hartmann's speculations are not supported, however. Shelley-Tremblay and Rosen (1996) note that many hunters use stealth, concentration and silence, and that ADHD behaviors would conflict with those requirements.

Shelley-Tremblay and Rosen (1996) describe different and more recent (in the last 100,000 years) selective pressures that may have favored ADHD behaviors. Aggression and impulsiveness may have been advantageous in displacing or eliminating other hominid populations such as Homo sapiens neanderthalensis. Some individuals with ADHD are aggressive (e.g., Faraone et al. 1997), and belligerence and combativeness may have been positively selected in a warring environment (ShelleyTremblay and Rosen 1996). Another setting where a few $\mathrm{ADHD}$ behaviors may have also been useful is based on the "aquatic ape theory" of Morgan (1972), in which early hominids may have avoided large mammalian predators by spending much of their time as tidal waders. Shelley-Tremblay and Rosen argue that the demands of the marine environment would have required closer ties between mother and child, and the typically relatively greater demands of the individual with ADHD for a mother's attention, as facilitated by excessive speech, would have been vital for offspring survival. 
Another more sophisticated version of Hartmann's theory is Jensen et al.'s (1997b:1675) description of the hypervigilant, high-scanning, impulsive, high-motor-active, "responseready" individual who functions well in unsafe, rapidly changing or novel circumstances. This would be in contrast to the low-motor-active, nonimpulsive, focused, attentive "problemsolver," who does best in safe, unchanging settings.

All authors who place ADHD behaviors in a positive framework imply that there may be many settings where these behaviors were selectively advantageous. Hartmann (1993) captures the essence of the various theories when he argues that ADHD is not a malfunction but a harmonious and functional response to different contexts. The issue under consideration is: how can it be advantageous in any setting to be unable to inhibit a response? Hyperactive children may make choices faster, but they also make more mistakes (reviewed in Sonuga-Barke et al. 1992). Would they make the right choice if stalked by a sabertoothed tiger? Irrelevant hypervocalization would attract a predator, and the reduced ability to read others in social settings might lead to other problems; impaired problem-solving would surely be a handicap over a lifetime. In addition, the slower internalization of speech and reduced capacity for analysis and synthesis (reconstitution) might diminish creativity.

Barkley (1997a,b) argues that all the behavioral correlates of individuals with ADHD reflected in the problem of impaired responses. In other words, an inability to self-regulate effectively underlies the impaired performance of the other "executive functions" originally described by Bronowski (1977). These functions include: prolongation, separation of affect, internalization, and reconstitution. These executive functions cannot be carried out well if the individual is less able to stop, reflect and adapt. Barkley's (1997a,b) more complete model convincingly places behavioral disinhibition as the central disability in individuals with ADHD. The differences in gross neuroanatomy between those with ADHD and unaffected individuals also seem to support a picture of impaired inhibition and attention, but they do not explain the relatively common comorbid conditions. Differences at the neurochemical level may explain these conditions.

\section{Dopamine and Related NeUrochemistry}

One of the neurotransmitters most frequently implicated in current ADHD research is dopamine (Morrison and Hof 1992; Ernst et al. 1998a,b; Vaidya et al. 1998). An understanding of dopamine's structure, relationship to other neurotransmitters, distribution in the brain, and mode of action clearly shows why a derangement in any aspect of dopamine activity affects multiple behavioral systems (Kischka et al. 1996; Castellanos 1997; Niedermeyer 1998). Furthermore, dopamine is intimately related to norepinephrine in structure (both are catecholamines), mode of synthesis (dopamine is hydroxylated to form norepinephrine), and even in neuromodulatory mode of action (Moises et al. 1981; Johnson and Napier 1997; Tanda et al. 1997). The interest in norepinephrine and its relationship to ADHD usually arises as a consequence of its involvement in more general aspects of attention (Parasuraman 1998; Aston-Jones et al. 1999).

The release of dopamine arises from axonic projections on dopaminergic neurons whose bodies lie in the ventral tegmental area and the substantia nigra (Thompson 1993). These neurons project axons through four principal pathways (with differing responsibilities): the nigrostriatal (movement), mesolimbic (learning), mesocortical (motivation reward), and tuberoinfundibular (hormone synthesis and release). Dysfunction in these pathways leads to a variety of neurological, psychiatric and endocrine disorders (Hazell 1997; Tannock 1998). Goldman-Rakic (1995) mapped dopaminergic innervation and found that the densest distribution of neurons in monkeys and humans is in the medial sectors, particularly the prefrontal cortex, with the caudate nucleus and the striatum containing the most dopamine (Wender 1971). Most important, dopamine availability can be diffuse and uniformly distributed to these varied areas (Grace 1991), so that modularized areas of the brain, which could, in principle, act independently of one another, are coordinately influenced (Servan-Schreiber et al. 1990). Since a pathology in some facet of dopamine metabolism would logically affect a number of apparently independent behavioral conditions (Blum et al. 1996), comorbidity is an extremely important area of ADD research (Blum et al. 1996; Hazell 1997). 
In addition, extensive heterogeneity has been observed in the $\mathrm{G}$ proteins associated with dopamine receptor function (Gudermann et al. 1997). In principle, this heterogeneity would lead to overlaps in modes of action, and either initiate opposition or reinforcement in activity. For example, decreased synthesis and release of dopamine could be offset, in principle, by increased receptor sensitivity, or amplified by increased transporter function. In a simplified perspective, the receptors would influence the extent of total dopaminergic activity in a particular region of the brain, but given the genetic complexity of the dopaminergic system (and the extensive distribution to cortical regions), one would certainly not expect any pathology involving dopamine to resolve itself into a single subtype of behavioral condition (Faraone et al. 1991; Comings 1995).

Confirmation of the importance of one or more of the putative genes in $\mathrm{ADHD}$ requires a disproportionate presence of these genes in individuals displaying the condition when compared with individuals not afflicted with the disorder. The approach of Comings et al. (1996) is representative of the process for solving a polygenic problem. Having investigated the impact of polymorphisms of three of the abovementioned genes, they found that conditions such as Tourette syndrome, stuttering, ADHD, conduct disorder, and oppositional defiant disorder are correlated with particular forms (polymorphisms) of genes associated with dopamine activity. The potential impact on the language area of the brain is particularly obvious in stuttering and Tourette syndrome.

Because of the unequivocal benefit of methylphenidate (or alternatively, d-amphetamine or pemoline) in ADHD therapy (Sykes et al. 1971; Klorman et al. 1979; Barkley 1990), and its interaction with the dopamine transporter (DAT), some investigators have focused upon possible deranged transporter function in ADHD. Both Gill et al. (1997) and Cook et al. (1995) have found that a particular polymorphism of the transporter DAT1 is associated with ADHD, and is transmitted between parents and offspring. Others have found particular dopamine receptor isoforms occurring in groups afflicted with ADHD. For example, LaHoste et al. (1996) have implicated a particular form of the $\mathrm{D} 4$ dopamine receptor (DRD4; 7-repeat allele) as being disproportionately represented in ADHD populations. Swanson et al. (1998) have recruited another sample of subjects with ADHD to replicate the findings of LaHoste et al. (1996). Barkley (1998b:3) also notes that researchers at different labs have replicated support for one marker, the DRD4-repeat region of the dopamine receptor gene, which is associated with the personality trait of "high novelty-seeking behavior." This gene is thought to influence "postsynaptic sensitivity" largely in the frontal and prefrontal cortex, which are both linked to executive functions and the attentional system. Twenty-nine percent of the ADHD samples have this repeat allele, double its rate in the general population.

Others have focused upon the enzymatic machinery involved in dopamine metabolism. Ernst et al. (1998a) monitored presynaptic concentrations of DOPA decarboxylase by using positron emission tomography (PET) to compare isotopic concentrations of a fluorinated analogue of DOPA in normal individuals and those with ADHD. They found evidence for abnormalities in dopamine metabolism in both samples, but abnormalities in dopamine metabolism in only the prefrontal cortex in 17 of the ADHD samples, in comparison to the 23 controls.

Finally, other researchers have attempted to concentrate on combinations of all genes concerned with dopamine activity. Perhaps the most ambitious effort is that of Comings et al. (1996), who followed receptor DRD2, enzyme dopamine-b-hydroxylase, and transporter DAT1 gene polymorphisms in Tourette probands and their relatives. They found significant associations between variations of the three genes and those afflicted with Tourette syndrome, ADHD, stuttering, oppositional defiant behavior, alcohol abuse, mania and general anxiety. These studies confirm what must be intuitively obvious: that these conditions have genetic underpinnings, are polygenic, and likely form a continuum that manifests itself in a variety of observed conditions, all interrelated.

\section{NOREPINEPHRINE AND RELATED NEUROCHEMISTRY}

One of the attentional system's principal locations in the brain is the locus coeruleus (LC), a cluster of noradrenergic neuron bod- 
ies in the brain stem that sends fibers to an assortment of areas in the brain (Posner and Petersen 1990; reviewed in Halperin 1996). Our arguments on attention largely follow the arguments of Aston-Jones et al. (1999), and are summarized in Figure 1. The extent of neurotransmission in the LC pathway depends upon the extent to which the animal is aroused and attentive to aspects of its external environment. Vegetative states with low attentional activity (Figure 1c) derive from decreased neurotransmission in the LC, and are characterized by little engagement with the sensory environment and the dominance of endogenously-driven programs (the most extreme of which would be sleep). Conversely, high attentional states result from increased neurotransmission in these nuclei, and produce a scanning or labile attentiveness (Figure 1c) that monitors potential threats from the environment. The fibers that leave the LC innervate much of the forebrain by way of the hippocampus and hypothalamus (Fuster 1989). The norepinephrine which is produced in the LC is released by these fibers and acts postsynaptically to affect the "signal-to-noise" ratio for forebrain target cells (Waterhouse et al. 1982).

Changes in signal-to-noise ratios in neurons may be all-important in issues of $\mathrm{ADHD}$, and warrant much further consideration. One of the principal features of both norepinephrine and dopamine is that both are neuromodulatory (Aston-Jones and Bloom 1981; Johnson and Napier 1997). Neuromodulators have little effect on their own, but when released into synapses where other neurotransmitters are active, they amplify strong external sensory signals and dampen weak internal signals (noise or endogenous neural activity), changing the signal-to-noise ratio (Figure 1a). This happens, presumably, through an increase in the activity of both excitatory and inhibitory neurotransmitters (such as glutamate and GABA, respectively) (Moises et al. 1981). The net result of such action is to strengthen the effect of strong impulses (presumably arriving from the LC) that provide sensory information regarding potentially threatening features (stimuli) from the external environment. But the attentiveness and focus associated with high LC output are complicated by the fact that a variety of sensory (olfactory, auditory, visual, tactile) inputs must be sampled within a short period of time. Therefore the behavioral result, ironically, would be a short attention span in which scanning or labile attentiveness assesses sequentially different types of sensory input (Aston-Jones et al. 1999).

This scanning or labile attentiveness logically would be derived at the expense of weak spontaneous internal stimuli (noise) arriving from other association areas within the brain, when LCstimulation is not maximal, and weak internal stimuli (noise) are not squelched by norepinephrine. Noise, or weak internal stimuli (arising as endogenous neural activity from a variety of cortical structures), would be required for maximum integration of analytical, creative, and integrative abilities. Such behavior would be viewed externally as stable focus and reliable task performance. The process might be characterized by a mixture of high LC activity, where specific auditory and visual sensory stimuli would be processed, alternating with low LC activity, where weak endogenous neural activity could be integrated. These alternating states of high and low norepinephrine activity would be characterized as phasic (Figure 1b) (Holdefer and Jacobs

Figure 1. NORADRENERGIC FUNCTION IN THE PREFRONTAL CORTEX.

a: The influence of norepinephrine (NE) upon signal-to-noise ratio. Arrow length is proportional to magnitude of sensory signal (auditory, visual, olfactory or tactile) from the locus coeruleus or magnitude of endogenous noise (creative associations, musings, interpretations, deductions and reflections). At low tonic concentrations of $\mathrm{NE}(\mathbf{b}$, left), external sensory stimuli (signals) are reduced relative to endogenous neural activity (endogenous noise), resulting in the activation of internally driven vegetative programs (relaxation, drowsiness or sleep) (c, left). At intermediate levels of NE, during which phasic release occurs (b, center), critical external stimuli (e.g., verbalizations and symbols) are amplified along with the amplification of critical endogenous activity (reflections and interpretations). Such activity would be viewed as focused, productive or creative (c, center). At high tonic levels of NE (b, right), external signals from the locus coeruleus are magnified relative to endogenous noise. This results in a scanning or labile attentiveness, in which sensory stimuli are searched for threat or danger (c, right). 


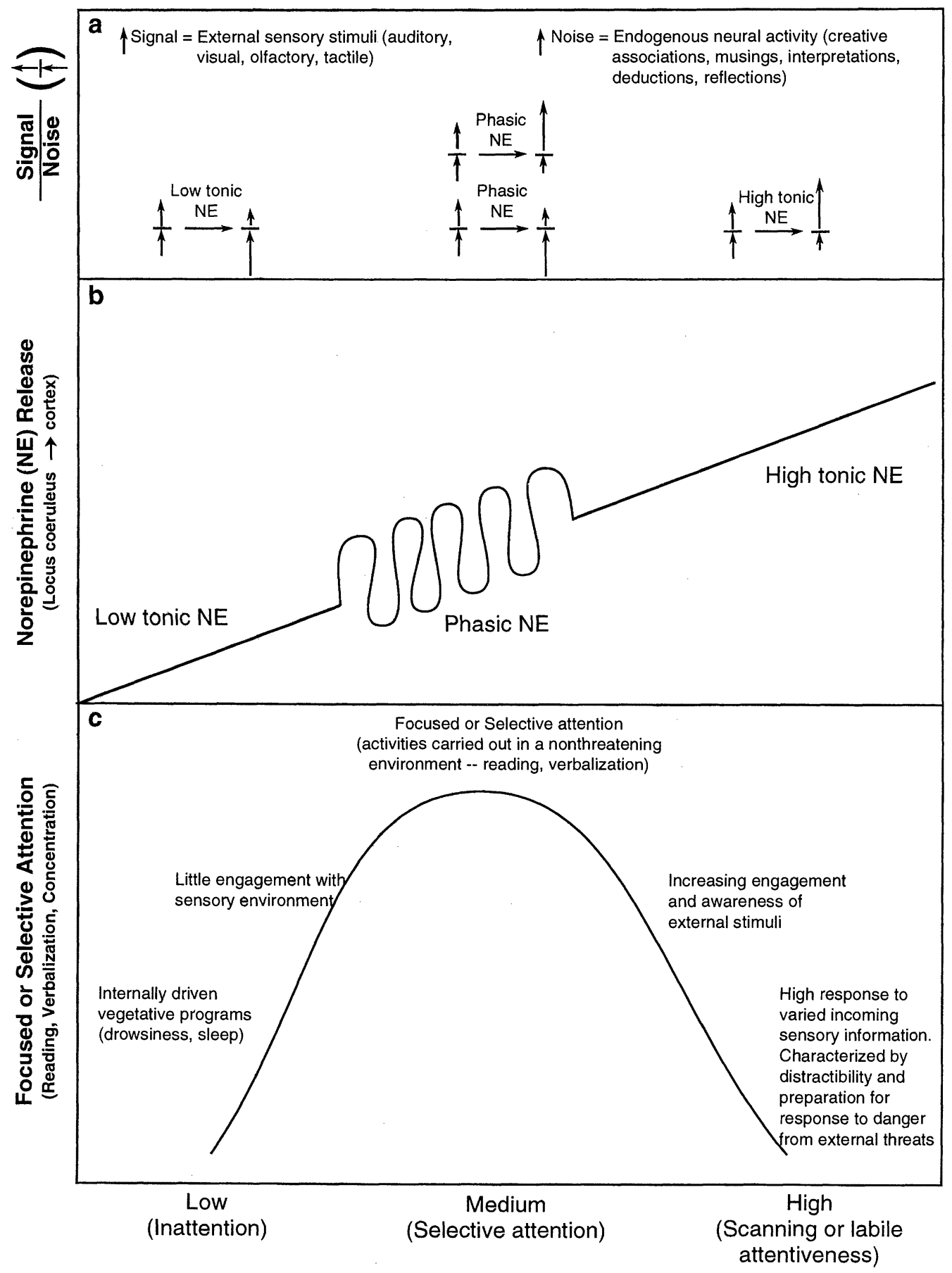

\section{Attentive State}


1994; Waterhouse et al. 1998). By this model, ADHD would arise not from a lack of stimulation from the LC, with its attendant focus and attentiveness, but rather from the kind of attentiveness and focus in which the LC mandates do not allow the addressing of nonthreatening tasks such as reading, writing, painting, and casual conversation. Forced by a kind of scanning focus that monitors potential threats from the environment, the LC prevents assessment of the relative value of different tasks, or follow-through in a lengthy, perhaps unrewarding, task. Much of ADHD can be explained by the view that it represents the behavior of an individual who is "stuck" in a scanning focus (Aston-Jones et al. 1999), processing and amplifying incoming stimuli (signals) and ignoring endogenous neural activity (noise).

\section{Conditions That Are Comorbid WITH ADHD}

Neurotransmitters play central roles in the interconnection of different subsystems in the brain, and it is these interrelationships that likely underlie the common comorbid conditions associated with $\mathrm{ADHD}$ and its linkage to language. The underlying physiology that explains why individuals with $\mathrm{ADD}$ are, to varying degrees, less adept in aspects of speech production, self-control, and sequencing and ordering of thoughts and behaviors, logically predicts that certain associated behaviors would reflect linked "wiring" features of the brain. First, depending on the severity of the "disability" and the interconnections within specific brains, reduced control should sometimes play out in reduced affective control in regulating aggression, frustration and moods. Second, if the latest fine-tuning of human selfcontrol is a side effect of the evolution of human communication, then some individuals will exhibit speech and language disabilities that extend beyond the typical lag in language development characteristic of individuals with ADHD. The comorbidity patterns clearly support these two assertions.

$\mathrm{ADHD}$ and other psychiatric conditions are often seen in the same person. Jensen et al. (1997a) and Caron and Rutter (1991) point out that comorbidity may be an artifact of or enhanced by sample selection or the ways that subjects are diagnosed. For example, behaviors with overlapping diagnoses can explain higher rates of comorbidity. Most research is on clinical populations that generally express severe psychopathology. Since individuals are often identified with more than one disorder ("Berkson's bias"), clinicians may be mistaken about the actual co-occurrence rates in the general population.

To partly control for this bias, Jensen et al. (1997a) examined studies of clinical and epidemiological populations to see whether these comorbid conditions are associated with ADHD. They found relatively few epidemiological studies, although all the samples found supported comorbidity between ADHD and oppositional defiant and conduct disorders, with comorbidity rates ranging from 42.7 to $93 \%$. Internalizing disorders (or problems "within the self") such as anxiety, separation anxiety and major depressive disorder occurred at lower frequencies (13.0 to 50.8\%), depending on which internalizing disorders were examined. Externalizing disorders (behaviors directed against others) such as conduct disorder (CD) and oppositional defiant disorder (ODD) were most common in males with $\mathrm{ADHD}$, and the internalizing disorders were more typical of females with ADHD. In addition, ODD and CD were exacerbated by maternal stress, depression, marital discord, generally negative parent-child interactions or family disadvantage, suggesting to Jensen et al. (1997a) that the severity of the disorder is affected by the local environment. They also found that those with aggressive behaviors respond positively to treatment. A similar correlation between psychosocial adversity and the number of ADHD symptoms, as well as comorbidity with depression, anxiety and other measures of dysfunction, also supported the significant role of environmental factors.

Biederman et al. (1991) have long noted familial associations between attention deficit disorders and many of the common comorbid conditions. Recently Biederman et al. (1998) argued that major depression is not a result of demoralization because of adversities posed by ADHD. A reduction in the symptoms associated with ADHD did not reduce the symptoms for major depression, which they feel indicates that the disorders are independent. The un- 
derlying physiology suggests that major depression reflects the action of a linked cognitive subsystem that can be impaired as a result of an inherited weakness (a likely shared weakness with $\mathrm{ADHD}$ ), as well as triggers in the local environment. Once initiated, the trajectory of the impairments would not necessarily mimic changes associated with ADHD.

Commonly comorbid with $\mathrm{ADHD}$, learning disabilities (LD) are suspected whenever a child's behavior is discrepant, defined as 1 to 2 standard deviations below the mean performance of same-aged children (Beitchman 1985). Many of these learning disabled children will exhibit delays in acquiring language skills which, according to Cantwell et al. (1979) and Cantwell and Baker (1987), place those children at risk for psychiatric problems. They note that $50 \%$ of children in speech and hearing clinics have diagnosable disorders according to the DSM-III, and that they are much more likely to have a behavioral disturbance, particularly ADD. Thus, hyperactivity is considered one of several subtypes of learning disabilities, typically found in about $39 \%$ of the LD population (e.g., August and Garfinkel 1990). Most clinicians assume that the wellestablished association between ADHD and school failure is largely a result of behavioral issues rather than learning difficulties that extend beyond attention problems (McGee and Share 1988). Cantwell and Baker (1987) compared children with only speech problems, children with only language problems, and those with both speech and language problems, and found that psychiatric disorders were most numerous in children with both speech and language problems. The rates of ADD were highest in children with language problems of any kind.

The relationship between language and psychiatric problems intrigued Beitchman and colleagues, and they proposed (like Cantwell) that both problems probably reflect an overall developmental lag. Beitchman et al. (1987) argued that only some hyperactive children suffer from a language delay that probably reflects overall developmental immaturity. Receptive language is close to grade level, but expressive language is slowed about one year on average. $\mathrm{ADD}$ is much higher in language-disordered clinic samples. Love and Thompson (1988) also note that $75 \%$ of language-disordered children exhibit ADD, whereas only $66.6 \%$ of ADD children are diagnosed with language disabilities.

Research then focused on whether there are "pure" subgroups of hyperactives who exhibit distinctive sets of language and/or learning disabilities (e.g., Tarnowski et al. 1986; Felton et al. 1987). The pattern of deficits differs from study to study, and there is extensive discussion on whether ADHD deficits directly affect school performance or are independent of it. Those who see ADHD as independent include Silver (1990), who proposes that "pure" subgroups of hyperactives are only emotionally disturbed and have no impairments in the ability to learn. O'Neill and Douglas (1991) argue that poor study habits are the source of the problem. Faraone et al. (1993) suggest that $\mathrm{ADHD}$ and $\mathrm{LD}$ are etiologically distinct, since the two disorders do not cosegregate in relatives of probands with both disorders; they believe that the patterns reflect nonrandom mating. More common are those who suggest that individuals with learning disabilities reflect ADHD cognitive deficits, including impairments in attention (e.g., Zentall 1993), self-inhibition (e.g., Pennington et al. 1993), and coding deficits (e.g., Javorsky 1993). Also associated is Central Auditory Processing Disorder, a condition in which individuals have difficulty processing what they hear. This often leads to problems in reading and phonology (Riccio and Hynd 1996). Gilberg et al. (1997) comment that "pure" groups of individuals with $\mathrm{ADHD}$ are difficult to identify and are usually the smallest subsample.

Also apparent is the increasing interest by speech pathologists and educators who, like Westby and Cutler (1994:60), point out that children with $\mathrm{ADHD}$ are particularly impaired in metacognitive ("planning, monitoring, and evaluating") and pragmatic (e.g., talking too much, not listening, unable to take turns, interrupting) behaviors; these impairments are language based and rule-governed. The idea that ADHD is considered mostly a psychologi$\mathrm{cal} /$ psychiatric disorder means that the behavioral difficulties overshadow the language and pragmatic communication difficulties (Javorsky 1996).

Finally, there is an extensive literature that 
supports the association between low IQ and psychiatric disorders, including hyperactivity (reviewed by Goodman et al. 1995). Hyperactivity, rather than anxiety or aggressive behaviors, is considered most likely to interfere with learning and IQ test performance, and yet the expected inverse relationship between hyperactivity and IQ is less clear than for conduct or emotional problems. Language skills and IQ are highly correlated, and the common comorbidity of ADHD and language impairments will complicate analyses (Beitchman et al. 1987).

In any event, most research on ADHD focuses on individuals with normal IQ, and it is usually stated as one of the controlled variables. Hyperactivity is probably the most common behavioral problem in low IQ individuals, however, and both low IQ and ADHD are associated with severe behavioral and emotional problems that continue over time (Aman et al. 1996). Benasich et al. (1993) examined "language impaired" and normal subjects from ages 4 to 8 years (initially matched for IQ), in order to study the development of language, learning and behavioral problems. Behavioral disturbance (including hyperactivity) persisted until age eight, but IQ declined only for the language impaired and not for normal children. Low IQ was also significantly associated with behavioral problems, which indicates a more prominent explanatory role for IQ relative to linguistic deficiencies. The literature seems to support that IQ exacerbates behavioral disturbances, but there has been little direct research on its impact in the expression of ADHD or behaviors that may be influenced by ADHD (but see Carter and Swanson 1995).

Above-average or gifted students are probably not targeted as often for behavioral services because they are not performing poorly enough to be noticed (Johnson 1988). More intelligent children may find ways to cope, although they might still benefit from clinical support. Coping strategies surely differ, depending on intelligence. Schatz and HamdanAllen (1995) find that "adaptive behaviors" vary among autistic, mentally retarded and normal children according to IQ level, and increasing age and IQ are associated with better performance. The increases in IQhave less impact on social functioning for autistic children relative to mentally retarded children, however. This may be consistent with the findings of Zentall and Gohs (1984:85), who note that "the difficulty hyperactive children have demonstrated in the role as receivers of information in referential communication tasks does not appear to be related to low IQ, poor motivation, or nonspecific impulsivity."

\section{An Evolutionary Context For ADHD}

Many wonder whether ADHD is a mental disorder, an artifact of overcrowded classrooms, or a product of the need to juggle multiple demands on one's time. Wakefield (1992a, 1992b, 1997) provides a framework for examining this question with his "harmful dysfunction" concept of mental disorder, in which harm is determined both from social values (the cultural context factors that affect its expression) and from whether there is an underlying behavioral or biological dysfunction (see also Richters and Cicchetti 1993). Dysfunction is defined as impairment in performing an act which is characteristic of the human species. Excluded are disorders completely determined by local cultural context (e.g., "drapetomania," or the mental condition incorrectly ascribed to runaway slaves in the mid-19th century).

Buss (1999:400-403) reviews four ways in which dysfunction is erroneously considered to underlie a mental disorder. Evolved functions may be operating normally but result in problems because of: 1) discrepancies in the demands of contemporary life relative to ancestral environments, 2) ordinary errors that accompany routine functioning of a mechanism, 3) perceived suffering even though the mechanism is operating normally, and 4) undesirable behaviors that may result from the operation of normal mechanisms. These possibilities must be ruled out in order to infer dysfunction in terms of Wakefield's model, but all assume that the underlying mechanism is operating normally.

To understand dysfunction, one must determine the evolutionary role of the biological feature in question, an analytical challenge that has been discussed extensively in the literature (e.g., Reeve and Sherman 1993). Learning to read is surely a culturally desired skill, though an inability to read, by itself, is not an obvious example of a harmful dysfunction. 
Rather it is more likely that there is an underlying flaw in a mental skill that interferes with the ability to learn to read (Wakefield 1997); thus, it is still a disorder. In order to rule out apparent dysfunction that may just reflect contextual influences, the "normal" range of expression for a specific behavioral trait, given individual differences in innate skill, drive and opportunity, must also be delineated. Children who express aggression (and are labeled with oppositional/defiant disorder) may be responding logically and adaptively to a difficult setting (Richters and Cicchetti 1993).

An enhanced ability to plan for and carry out goals is obviously adaptive, and has become quite sophisticated. Monkeys and apes have an impressive array of cognitive abilities that distinguish them from most other mammals, but their self-regulatory abilities are only a fraction of those of a typical adult human being (Tomasello and Call 1997). How might language play a role in this ability to self-regulate? Berk and Potts (1991) argue that private speech and its development in individuals is critical for the development of self-control. In 1934, Vygotsky was the first to fully develop the idea that the evolution of language is key to the expansion of the uniquely human mental processes. He was reacting to the writings of his contemporary, Piaget (1926), who coined the term "egocentric speech (ES)," and who believed that ES was self-centered and internally driven rather than sensitive to social context. Piaget concluded ES was not an important aspect of a child's development. By contrast, Vygotsky (Berk 1992:18) considered ES a necessary transition from communicating socially to regulating oneself in order to carry out goals and, thus, ES became the foundation for the more sophisticated cognitive processes that included, for example, selective attention, planning, and self-reflection. The term "egocentric speech" has been replaced by "private speech," and empirical support for his premise is increasing.

Vygotsky (1934) suggested that the internal dialogue shifts from speech directed at oneself (that is responsive to social expectations) to a subvocal dialogue that continues to be an important aspect of self-regulation. Private speech may initially be an outlet for stress, but it eventually becomes anticipatory and central to the planning and execution of tasks (Berk 1992). This transition is developmentally determined and responsive to social context (e.g., Manning and White 1990). Clinicians in the U.S. have now decided that parenting has less to do with its expression and that genetic factors are largely responsible (reviewed by Hallowell and Ratey 1994). However, preliminary studies clearly support the developmental aspects of private speech and its close relationship to behavioral regulation (e.g., Duncan and Pratt 1997).

Self-inhibition is partly carried out through the regulation of attention, and thus both selfinhibition and attention are complementary. In 1890, James noted that attention involved moving between different threads of consciousness and focusing on one or another in a deliberately conscious way-this means simultaneously suppressing other threads while focusing on one or a few; in other words, inhibition is the other side of attention. Broadbent (1958) emphasized that focusing on one or a few threads might reflect a limited "working memory." Thus, filtering irrelevant from relevant stimuli is partly an adaptation to a limited holding capacity (short-term memory). Language cannot be detached from this process because language mediates how we focus our attention (Logan 1995; Fischler 1998). An individual's attention can be focused on some activities, but this focus inevitably occurs at the expense of others. The addition of language to this juggling act must have had a profound impact upon mental function. Both spatial and language tasks require activation of the same attentional areas of the brain (reviewed by Fischler 1998). In trying to complete a task that involves semantic assessment of words, such as generating possible uses of visually presented nouns (for example, an image of a hammer suggesting its use as a pounding tool), the frontal lobe activates well before the parietotemporal areas, which suggests that more automatic responses need to be inhibited before appropriate and original words can be generated (Snyder et al. 1995). In other words, brain activity varies, depending on whether it is automatic or requires attention. Language processes compete with other cognitive activities for the attentional system, and thus the evolution of language cannot be independent of the evolution of the human attentional system. 
Communicating regularly with strangers in increasingly sophisticated and subtle kinds of social interactions has presented new challenges to the linked systems in the brain that are responsible for the appropriate behaviors. Selection has probably favored those individuals better able to filter the significant from the insignificant and to suppress automatic language responses in order to generate ways of expressing new ideas. Individuals with ADHD have trouble "keeping up," but do their differences in neuroanatomy and biochemistry (and resulting behaviors) reflect normal functioning for what the system was adapted to do, or do they suggest dysfunction? We suggest that ADHD behaviors reflect dysfunction at the biochemical level (minimally), expressed as changes to development and neuroanatomy in ways that impair the cognitive processes that coordinate behaviors for assessing social context and communicating with others. In some cases this impairment is so debilitating that the individual requests or attracts the attention of clinicians.

If $\mathrm{ADHD}$ is a disorder of communication, then there are implications for diagnosis and treatment. First, every individual who is identified with this disorder should be tested with a wide battery of instruments. Speech pathologists and educators should always be part of the team since they are better able to evaluate and treat the metacognitive and pragmatic deficits. Second, early diagnosis will lead to earlier intervention so that parents and counselors can find positive ways of interacting with the "difficult" child. Intervention can ameliorate if not eliminate some of the accompanying behavioral problems like aggression or anxiety that are apparently partly triggered or exacerbated by difficult environments. Third, the pragmatic difficulties that individuals with
ADHD experience should be given more prominence in counseling programs. Being socially inept is not ordinarily considered a clinically relevant issue except in extreme cases, but for many individuals with $\mathrm{ADHD}$, pragmatic deficits may synergistically interact with and aggravate other behavioral problems, perhaps compounding the physiological deficits.

\section{Conclusions}

The proximate factors affecting the expression of ADHD behaviors seem to center upon difficulties in self-inhibition. The underlying anatomy implicates the prefrontal cortex, basal ganglia and cerebellum, and possibly both the dopaminergic and noradrenergic systems. There is much overlap and coordination between the areas of the brain for both language and attention/inhibition, and the areas of the brain considered to be impaired in individuals with ADHD. The dopaminergic and noradrenergic neurotransmitter systems may be key to understanding the associations between attention/inhibition and many of the comorbid conditions. Individuals with ADHD have maladaptive deficits at the biochemical, anatomical and behavioral levels that, although sometimes subtle, cause problems in a variety of social contexts. The disorder does not represent normal action gone awry. Individuals adapt to their condition with varying degrees of success, but their difficulties fit Wakefield's concept of "harmful dysfunction." More research and clinical attention should be paid to the communicative and comorbid conditions.

\section{ACKNOWLEDGMENTS}

We would like to thank Frank Haulgren, Crystal Pankowski, and Dana Fogg of Western Washington University's Library staff for their kind assistance in the acquisition of articles, and Tracy Finch of the Bureau for Faculty Research for her help with the illustration.

\section{REFERENCES}

Aman M G, Pejeau C, Osborne P, Rojahn J. 1996. Four-year follow-up of children with low intelligence and ADHD. Research in Developmental Disabilities 17:417-432.

APA [American Psychiatric Association]. 1968. Diagnostic and Statistical Manual of Mental DisordersII. Second Edition. Washington (DC): American Psychiatric Association.
APA [American Psychiatric Association]. 1980. Diagnostic and Statistical Manual of Mental DisordersIII. Third Edition. Washington (DC): American Psychiatric Association.

APA [American Psychiatric Association]. 1987. Diagnostic and Statistical Manual of Mental DisordersIII-R. Third Edition Revised. Washington (DC): American Psychiatric Association. 
APA [American Psychiatric Association]. 1994. Diagnostic and Statistical Manual of Mental Disorders$I V$. Fourth Edition. Washington (DC): American Psychiatric Association.

Aston-Jones G S, Bloom F E. 1981. Norepinephrinecontaining locus coeruleus neurons in behaving rats exhibit pronounced responses to nonnoxious environmental stimuli. Journal of Neuroscience 1:887-900.

Aston-Jones G S, Desimone R, Driver J, Luck S J, Posner M I. 1999. Attention. Pages 1385-1409 in Fundamental Neuroscience, edited by MJ Zigmond et al. New York: Academic Press.

August G J, Garfinkel B D. 1990. Comorbidity of $\mathrm{ADHD}$ and reading-disability among clinicreferred children. Journal of Abnormal Child Psychology 18:29-45.

Barkley R A. 1977. A review of stimulant drug research with hyperactive children. Journal of Child Psychology and Psychiatry 18:137-165.

Barkley RA. 1990. Attention-Deficit Hyperactivity Disorder: A Handbook for Diagnosis and Treatment. New York: Guilford Press.

Barkley R A. 1994a. History. Pages 3-38 in AttentionDeficit Hyperactivity Disorder: A Handbook for Diagnosis and Treatment, edited by R A Barkley. New York: Guilford Press.

Barkley R A. 1994b. Impaired delayed responding: a unified theory of attention-deficit hyperactivity disorder. Pages 11-57 in Dismuptive Behavior Disorders in Childhood, edited by D K Routh. New York: Plenum Press.

Barkley R A. 1997a. Attention-deficit/hyperactivity disorder, self-regulation, and time: toward a more comprehensive theory. Developmental and Behavioral Pediatrics 18:271-279.

Barkley RA. 1997b. ADHD and the Nature of Self-Control. New York: Guilford Press.

Barkley R A. 1998a. The prevalence of ADHD: is it just a U.S. disorder? The ADHD Report 6(2):1-6.

Barkley R A. 1998b. Gene linked to ADHD verified. The ADHD Report 6(3):1-5.

Barkley R A, DuPaul G J, McMurray M B. 1990. A comprehensive evaluation of attention deficit disorder with and without hyperactivity. Journal of Consulting and Clinical Psychology 58:775-789.

Beiderman J, Faraone S V, Keenan K, Tsuang M T. 1991. Evidence of familial association between attention deficit disorder and major affective disorders. Archives of General Psychiatry 48:633-642.

Beiderman J, Mick E, Faraone SV. 1998. Depression in attention deficit hyperactivity disorder (ADHD) children: "true" depression or demoralization? Journal of Affective Disorders 47:113-122.

Beitchman J. 1985. Speech and language impairment and psychiatric risk. Psychiatric Clinics of North America 8:721-735.

Beitchman J, Tuckett M, Batth S. 1987. Language delay and hyperactivity in preschoolers: evi- dence for a distinct subgroup of hyperactives. Canadian Journal of Psychiatry 32:683-687.

Benasich A A, Curtiss S, Tallal P. 1993. Language, learning, and behavioral disturbances in childhood: a longitudinal perspective. Journal of the American Academy of Child and Adolescent Psychiatry 32:585-594.

Berk L E. 1992. Children's private speech: an overview of theory and the status of research. Pages 17-53 in Private Speech: From Social Interaction to Self Regulation, edited by R M Diaz and L E Berk. Hillsdale (NJ): Lawrence Erlbaum Associates.

Berk L E, Potts M K. 1991. Development and functional significance of private speech among attention-deficit hyperactivity disordered and normal boys. Journal of Abnormal Child Psychology 19: 357-377.

Berquin P C, Giedd J N, Jacobsen L K, Hamburger S D, Krain B A, Rapoport J L, Castellanos F X. 1998. Cerebellum in attention-deficit hyperactivity disorder: a morphometric MRI study. Neurology 50:1087-1093.

Blum K, Cull J G, Braverman E R, Comings D E. 1996. Reward deficiency syndrome. American Scientist 84:132-145.

Bradley W. 1937. The behavior of children receiving Benzedrine. American Joumal of Psychiatry 94:577585.

Broadbent D E. 1958. Perception and Communication. Oxford: Pergamon Press.

Bronowski J. 1977. Human and animal languages. Pages 104-131 in A Sense of the Future, edited by J Bronowski. Cambridge (MA): MIT Press. [First appeared in To Honor Roman Jakobson, Volume 1 (1967), The Hague: Mouton].

Buss D M. 1999. Evolutionary Psychology: The New Science of Mind. Boston: Allyn and Bacon.

Cantwell D P, Baker L. 1987. Prevalence and type of psychiatric disorder and developmental disorders in three speech and language groups. Journal of Communication Disorders 20:151-160.

Cantwell D P, Baker L, Mattison R. 1979. The prevalence of psychiatric disorder in children with speech and language disorder: an epidemiological study. Journal of the American Academy of Child Psychiatry 18:450-461.

Caron C, Rutter M. 1991. Comorbidity in child psychopathology: concepts, issues and research strategies. Journal of Child Psychology and Psychiatry 32: 1063-1080.

Carter J D, Swanson H L. 1995. The relationship between intelligence and vigilance in children at risk. Journal of Abnormal Child Psychology 23:201-220.

Casey B J, Castellanos F X, Giedd J N, Marsh W L, Hamburger S D, Schubert A B, Vauss Y C, Vaituzis A C, Dickstein D P, Sarfatti SE, Rapoport J L. 1997. Implication of right frontostriatal circuitry in response inhibition and attention-deficit/hyperactivity disorder. Joumal of American Academy of Child and Adolescent Psychiatry 36:374-383. 
Castellanos F X. 1997. Toward a pathophysiology of attention-deficit/hyperactivity disorder. Clinical Pediatrics 36:381-393.

Castellanos F X, Giedd J N, Marsh W L, Hamburger S D, Vaituzis A C, Dickstein D P, Sarfatti S E, Vauss Y C, Snell J W, Lange N, Kaysen D, Krain A L, Ritchie G F, Rajapakse J C, Rapoport J L. 1996. Quantitative brain magnetic resonance imaging in attention-deficit hyperactivity disorder. Archives of General Psychiatry 53:607-616.

Comings D E. 1995. The role of genetic factors in conduct disorder based on studies of Tourette syndrome and attention-deficit hyperactivity disorder probands and their relatives. Development and Behavioral Pediatrics 16:142-157.

Comings D E, Wu S, Chiu C, Ring R H, Gade R, Ahn C, MacMurray J P, Dietz G, Muhleman D. 1996. Polygenic inheritance of Tourette syndrome, stuttering, attention deficit hyperactivity, conduct and oppositional defiant disorder: the additive and subtractive effect of the three dopaminergic genes-DRD2, DbH, and DAT1. American Journal of Medical Genetics 67:264-288.

Cook E H, Jr, Stein M A, Krasowski M D, Cox N J, Olkon D M, Kieffer J E, Leventhal B L. 1995. Association of attention-deficit disorder and the dopamine transporter gene. American Journal of Human Genetics 56:993-998.

Corballis M C. 1999. The gestural origins of language. American Scientist 87:138-145.

Crow TJ. 1997. Is schizophrenia the price that Homo sapiens pays for language? Schizophrenia Research 28:127-141.

Deacon T W. 1997. The Symbolic Species: The Co-evolution of Language and the Brain. New York: W. W. Norton and Company.

Denckla M B. 1996. A theory and model of executive function: a neuropsychological perspective. Pages 263-277 in Attention, Memory, and Executive Function, edited by G R Lyon and NA Krasnegor. Baltimore: Paul H. Brookes.

Douglas V I. 1972. Stop, look and listen: the problem of sustained attention and impulse control in hyperactive and normal children. Canadian Journal of Behavioral Sciences 4:259-282.

Douglas V I. 1983. Attention and cognitive problems. Pages 280-329 in Developmental Neuropsychiatry, edited by M Rutter. New York: Guilford Press.

Douglas V I. 1988. Cognitive deficits in children with attention deficit disorder with hyperactivity. Pages 65-82 in Attention Deficit Disorder: Criteria, Cognition, Intervention, edited by L M Bloomingdale and J A Sergeant. London: Pergamon Press.

Duncan R M, Pratt M W. 1997. Microgenetic change in the quantity and quality of preschoolers' private speech. International Journal of Behavioral Development 20:367-383.

Ernst M, Zametkin A J, Matochik J A, Jons P H, Cohen R M. 1998a. DOPA decarboxylase activity in attention deficit hyperactivity disorder adults. A [fluorine-18] fluorodopa positron emission tomographic study. Journal of Neuroscience 18:5901-5907.

Ernst M, Zametkin A J, Phillips R L, Cohen R M. $1998 \mathrm{~b}$. Age-related changes in brain glucose metabolism in adults with attention-deficit/hyperactivity disorder and control subjects. Journal of Neuropsychiatry 10:168-177.

Faraone S V, Biederman J, Jetton J G, Tsuang M T. 1997. Attention deficit disorder and conduct disorder: longitudinal evidence for a family subtype. Psychological Medicine 27:291-300.

Faraone S V, Biederman J, Keenan K, Tsuang M T. 1991. Separation of DSM-III attention deficit disorder and conduct disorder-evidence from a family-genetic study of American child psychiatric-patients. Psychological Medicine 21:109-121.

Faraone S V, Biederman J, Lehman B K, Spencer T, Norman D, Seidman L J, Kraus I, Perrin J, Chen W J, Tsuang M T. 1993. Intellectual performance and school failure in children with attention deficit hyperactivity disorder and in their siblings. American Journal of Psychiatry 102:616-623.

Felton R H, Wood F B, Brown I S, Campbell S K, Harter M R. 1987. Separate verbal memory and naming deficits in attention deficit disorder and reading disability. Brain and Language 31:171-184.

Fischler I. 1998. Attention and language. Pages 381399 in The Attentive Brain, edited by R Parasuraman. Cambridge (MA): MIT Press.

Fuster J M. 1989. The Prefrontal Cortex. New York: Raven Press.

Fuster J M. 1995. Memory and planning: two temporal perspectives of frontal lobe function. Pages 9-18 in Epilepsy and the Functional Anatomy of the Frontal Lobe, edited by H HJasper etal. NewYork: Raven Press.

Gilberg C, Melander H, von Knorring A, Janols L, Thernlund G, Häggölf B, Eidevall-Wallin L, Gustafsson P, Kopp S. 1997. Long-term stimulant treatment of children with attention-deficit hyperactivity disorder symptoms. Archives of General Psychiatry 54:857-864.

Gill M, Daly G, Heron S, Hawi Z, Fitzgerald M. 1997. Confirmation of association between attention deficit hyperactivity disorder and a dopamine transporter polymorphism. Molecular Psychiatry 2:311-313.

Goldman L S, Genel M, Bezman R J, Slanetz P J. 1998. Diagnosis and treatment of attention-deficit/hyperactivity disorder in children and adolescents. Journal of the American Medical Association 279:1100-1107.

Goldman-Rakic P S. 1995. Anatomical and functional circuits in prefrontal cortex of nonhuman primates. Pages 51-65 in Epilepsy and the Functional Anatomy of the Frontal Lobe, edited by $\mathrm{H} \mathrm{H}$ Jasper et al. New York: Raven Press. 
Goodman R, Simonoff E, Stevenson J. 1995. The impact of child IQ, parent IQ and sibling IQ on child behavioural deviance scores. Jourmal of Child Psychology and Psychiatry and Allied Disciplines 36: 409-425.

Grace A A. 1991. Phasic versus tonic dopamine release and the modulation of dopamine system responsivity. Neuroscience 41:1-24.

Gualtieri C T, Hicks R E. 1985. Neuropharmacology of methylphenidate and a neural substrate for childhood hyperactivity. Psychiatric Clinics of North America 8:875-892.

Gudermann T, Schöneberg T, Schultz G. 1997. Functional and structural complexity of signal transduction via G-protein-coupled receptors. Annual Review of Neuroscience 20: 399-427.

Hallowell E, RateyJ. 1994. Driven To Distraction. New York: Touchstone.

Halperin J M. 1996. Conceptualizing, describing, and measuring components of attention: a summary. Pages 119-136 in Attention, Memory, and Executive Function, edited by G R Lyon and N A Krasnegor. Baltimore: Paul H. Brookes.

Hart E L, Lahey B B, Loeber R, Applegate B, Frick P J. 1995. Developmental changes in attentiondeficit hyperactivity disorder in boys: a four-year longitudinal study. Journal of Abnormal Child Psychology 23:729-750.

Hartmann T. 1993. Attention Deficit Disorder: A Different Perception. Lancaster (UK): Underwood-Miller.

Hazell P. 1997. The overlap of attention deficit hyperactivity disorder with other common mental disorders. Joumal of Pediatrics and Child Health 33:131-137.

Heilman K M, Voeller K K S, Nadeau S E. 1991. A possible pathophysiological substrate of attention deficit hyperactivity disorder. Joumal of Child Neurology 6:74-79.

Holdefer R N, Jacobs B L. 1994. Phasic stimulation of the locus coeruleus: effects on activity in the lateral geniculate nucleus. Experimental Brain Research 100:444-452.

James W. 1890. The Principles of Psychology. [1992 reprint]. Chicago: Encyclopedia Britannica.

Javorsky J. 1993. Linguistic coding deficits in children with attention deficit hyperactivity disorder: a case for comorbidity of language learning disabilities and ADHD. ADHD Report 4:8-9.

Javorsky J. 1996. An examination of youth with attention-deficit/hyperactivity disorder and language learning disabilities: a clinical study. Journal of Learning Disabilities 29:247-258.

Jensen P S, Martin D, Cantwell D P. 1997a. Comorbidity in ADHD: implications for research, practice, and DSM-V. Journal of the American Academy of Child and Adolescent Psychiatry 36:1065-1079.

Jensen P S, Mrazek D, Knapp P K, Steinberg L, Pfeffer C, Schowalter J, Shapiro T. 1997b. Evolution and revolution in child psychiatry: $\mathrm{ADHD}$ as a disorder of adaptation. Journal of the American Academy of Child and Adolescent Psychiatry 36:16721679.

Johnson D J. 1988. Review of research on specific reading, writing, and mathematics disorders. Pages 79-163 in Learning Disabilities: Proceedings of the National Conference, edited by J F Kavanagh and T J Truss, Jr. Parkton (MD): Yorkton Press.

Johnson P I, Napier T C. 1997. GABA- and glutamateevoked responses in the rat ventral pallidum are modulated by dopamine. European Journal of Neuroscience 9:1397-1406.

Kischka U, Kammer T, Maier S, Weisbrod M, Thimm M, Spitzer M. 1996. Dopaminergic modulation of semantic network activation. Neuropsychologia 34:1107-1113.

Klorman R, Salzman L F, Pass H L, Borgstedt A D, Dainer K G. 1979. Effects of methylphenidate on hyperactive children's evoked responses during passive and active attention. Psychophysiology 16: 23-29.

LaHoste G J, Swanson J M, Wigal S B, Glabe C, Wigal T, King N, Kennedy J L. 1996. Dopamine D4 receptor gene polymorphism is associated with attention deficit hyperactivity disorder. Molecular Psychiatry 1:121-124.

Levy F, Hay D F, McStephen M, Wood C, Waldman I. 1997. Attention-deficit hyperactivity disorder: a category or a continuum? Genetic analysis of a large-scale twin study. Journal of the American Academy of Child and Adolescent Psychiatry 36:737744.

Logan G D. 1995. Linguistic and conceptual control of visual spatial attention. Cognitive Psychology 28:103-174.

Love A J, Thompson M G G. 1988. Language disorders and attention deficit disorders in young children referred for psychiatric services: analysis of prevalence and a conceptual synthesis. American Journal of Orthopsychiatry 58:52-64.

Manning B H, White C S. 1990. Task-relevant private speech as a function of age and sociability. Psychology in the Schools 27:365-372.

McGee R, Share D L. 1988. Attention deficit disorder-hyperactivity and academic failure: which comes first and what should be treated? Journal of the American Academy of Child and Adolescent Psychiatry 27:318-325.

Milberger S, Biederman J, Faraone S V, Guite J, Tsuang M T. 1997. Pregnancy, delivery and infancy complications and attention deficit hyperactivity disorder: issues of gene-environment interaction. Biological Psychiatry 41:65-75.

Moises H C, Waterhouse B D, Woodward D J. 1981. Locus coeruleus stimulation potentiates Purkinje cell responses to afferent input: the climbing fiber system. Brain Research 222:43-64. 
Morgan E. 1972. The Descent of Woman. New York: Stein and Day.

Morrison J H, Hof P R. 1992. The organization of cerebral cortex: from molecules to circuits. Discussions in Neuroscience 9:7-79.

Niedermeyer E. 1998. Frontal lobe functions and dysfunctions. Clinical Electroencephalography 29:7990.

O’Neill M E, Douglas VI. 1991. Study strategies and story recall in attention deficit disorder and reading disability. Journal of Abnormal Child Psychology 19:671-692.

Parasuraman R. 1998. The Attentive Brain. Boston: MIT Press.

Pennington B F, Groisser D, Welsh M C. 1993. Contrasting cognitive deficits in attention deficit hyperactivity disorder versus reading disability. $D e-$ velopmental Psychology 3:511-523.

Piaget J. 1926. The Language and Thought of the Child. New York: Harcourt Brace.

Pontius A A. 1973. Dysfunction patterns analogous to frontal lobe system and caudate nucleus syndromes in some groups of minimal brain dysfunction. Journal of the American Medical Women Association 28:285-292.

Posner M I, Petersen S E. 1990. The attention system of the human brain. Annual Review of Neuroscience 13:25-42.

Quay H C. 1988. Attention deficit disorder and the behavioral inhibition system: the relevance of the neuropsychological theory of Jeffrey A. Gray. Pages 117-126 in Attention Deficit Disorder: Criteria, Cognition, Intervention, edited by L M Bloomingdale and J Sergeant. New York: Pergamon Press.

Quay H C. 1997. Inhibition and attention deficit hyperactivity disorder. Journal of Abnormal Child Psychology 25:7-13.

Reeve H K, Sherman P W. 1993. Adaptation and the goals of evolutionary research. Quarterly Review of Biology 68:1-32.

Riccio C A, Hynd G W. 1996. Relationship between ADHD and Central Auditory Processing Disorder: a review of the literature. School Psychology International 17:235-252.

Richters J E, Arnold L E, Jensen P S, Abikoff H, Conners C K, Greenhill L L, Hechtman L, Hinshaw S P, Pelham W E, Swanson J M. 1995. National Institute of Mental Health collaborative multisite, multimodal treatment study of children with ADHD: I. background and rationale. Journal of the American Academy of Child and Adolescent Psychiatry 34:987-1000.

Richters J E, Cicchetti D. 1993. Mark Twain meets DSM-III-R: conduct disorder, development, and the concept of harmful dysfunction. Development and Psychopathology 5:5-29.
Schachar R J, Tannock R, Marriot M, Logan G. 1995. Deficient inhibitory control in attention deficit hyperactivity disorder. Journal of Abnormal Child Psychology 23:411-438.

Schatz J, Hamdan-Allen G. 1995. Effects of age and IQ on adaptive behavior domains for children with autism. Journal of Autism and Developmental Disorders 25:51-60.

Servan-Schreiber D, Printz H, Cohen J D. 1990. A network model of catecholamine effects: gain, signal-to-noise ratio and behavior. Science 249: 892-895.

Shelley-Tremblay J F, Rosen L A. 1996. Attention deficit hyperactivity disorder: an evolutionary perspective. Journal of Genetic Psychology 157:443-453.

Silver L B. 1990. Attention deficit-hyperactivity disorder: is it a learning disability or a related disorder? Journal of Learning Disabilities 23:394-397.

Snyder A Z, Abdullaev Y G, Posner M I, Raichle M E. 1995. Scalp electrical potentials reflect regional cerebral flood-flow responses during processing of written words. Proceedings of the National Academy of Sciences of the United States of America 92: 1689-1693.

Sonuga-Barke E J S, Taylor E, Sembi S, Smith J. 1992. Hyperactivity and delay aversion: I. the effect of delay on choice. Journal of Child Psychology and Psychiatry 33:387-398.

Swanson J M, Sunohara G A, Kennedy J L, Regino R, Fineberg E, Wigal T, Lerner M, Williams L, LaHoste G J, Wigal S. 1998. Association of the dopamine receptor D4 (DRD4) gene with a refined phenotype of attention deficit hyperactivity disorder (ADHD): a family based approach. Molecular Psychiatry 3:38-41.

Sykes D H, Douglas V I, Weiss G, Minde K. 1971. Attention in hyperactive children and the effect of methylphenidate (Ritalin). Journal of Child Psychology and Psychiatry 12:129-39.

Szatmari P. 1992. The epidemiology of attentiondeficit hyperactive disorders. Pages 361-371 in Child and Adolescent Psychiatry Clinics of North America: Attention Deficit Hyperactivity Disorder, edited by G Weiss. Philadelphia: Saunders.

Tanda G, Pontiere F E, Frau R, DeChiara G. 1997. Contribution of blockade of the noradrenaline carrier to the increase of extracellular dopamine in the rat prefrontal cortex by amphetamine and cocaine. European Journal of Neuroscience 9:2077-2085.

Tannock R. 1998. Attention deficit hyperactivity disorder: advances in cognitive, neurobiological and genetic research. Journal of Child Psychology and Psychiatry 39:65-99.

Tarnowski K J, Prinz R J, Nay S M. 1986. Comparative analysis of attentional deficits in hyperactive and learning-disabled children. Journal of Abnormal Psychology 95:341-345. 
Thompson R F. 1993. Page 133 in The Brain: A Neuroscience Primer. Second Edition. New York: W. H. Freeman.

Tomasello M, Call J. 1997. Primate Cognition. New York: Oxford University Press.

Vaidya C J, Austin G, Kirkorian G, Ridlehuber H W, Desmond J E, Glover G H, Gabrieli J D E. 1998. Selective effects of methylphenidate in attention deficit hyperactivity disorder: a functional magnetic resonance study. Proceedings of the $\mathrm{Na}$ tional Academy of Science of the United States of America 95:14494-14499.

Vygotsky L S. 1934. Thought and Language. [1962 reprint]. Cambridge (MA): Harvard University Press.

Wakefield J C. 1992a. The concept of mental disorder: on the boundary between biological facts and social values. American Psychologist 47:373-388.

Wakefield J C. 1992b. Disorder as harmful dysfunction: a conceptual critique of DSM-III-R's definition of mental disorder. Psychological Review 99: 232-247.

Wakefield J C. 1997. When is development disordered? Developmental psychopathology and the harmful dysfunction and analysis of mental disorder. Development and Psychopathology 9:269-290.

Waterhouse B D, Moises H C, Woodward D J. 1998. Phasic activation of the locus coeruleus enhances responses of primary sensory cortical neurons to peripheral receptive field stimulation. Brain Research 790:33-44.

Waterhouse B D, Moises H C, Yeh H H, Woodward D J. 1982. Norepinephrine enhancement of inhibitory synaptic mechanisms in cerebellum and cerebral cortex: mediation by b-adrenergic receptors. Journal of Pharmacology and Experimental Therapeutics 221:495-506.

Welsh M C, Pennington B F. 1988. Assessing frontal lobe functioning in children: views from developmental psychology. Developmental Neuropsychology 4:199-230.

Wender P H. 1971. Minimal Brain Dysfunction in Children. New York: Wiley.

Westby C E, Cutler S K. 1994. Language and ADHD: understanding the bases and treatment of selfregulatory deficits. Topics of Language Disorders 14:58-76.

Wilens T E, Biederman J, Spencer T J, Prince J. 1995. Pharmacotherapy of adult attention deficit/hyperactivity disorder: a review. Joumal of Clinical Psychopharmacology 15:270-279.

Zametkin A J, Liebenauer L L, Fitzgerald G A, King A C, Minkunas D V, Herscovitch P, Yamada E M, Cohen R M. 1993. Brain metabolism in teenagers with attention-deficit hyperactivity disorder. Archives of General Psychiatry 50:333-340.

Zametkin AJ, Nordahl T E, Gross M, King A C, Semple W E, Rumsey J, Hamburger S, Cohen R M. 1990. Cerebral glucose metabolism in adults with hyperactivity of childhood onset. New England Journal of Medicine 323:1361-1366.

Zentall S S. 1993. Research on the educational implications of attention deficit hyperactivity disorder. Exceptional Children 60:143-153.

Zentall S S, Gohs D E. 1984. Hyperactive and comparison children's response to detailed vs. global cues in communication tasks. Learning Disability Quarterly 7:77-87. 